\title{
BMJ Global Health Flourishing: migration and health in social context
}

\author{
Sarah S Willen (D) , ${ }^{1}$ Nasima Selim (D) , ${ }^{2}$ Emily Mendenhall (D) , ${ }^{3}$ \\ Miriam Magaña Lopez, ${ }^{4}$ Shahanoor Akter Chowdhury, ${ }^{5}$ Hansjörg Dilger (1) , ${ }^{2}$ On \\ behalf of the Migration and Health in Social Context Working Group
}

To cite: Willen SS, Selim N, Mendenhall E, et al. Flourishing: migration and health in social context. BMJ Global Health 2021;6:e005108. doi:10.1136/ bmjgh-2021-005108

This article is submitted as part of the BMJ Global Health "Migration and Health in Social Context" collection edited by Emily Mendenhall and Seth M. Holmes.

Received 25 January 2021 Accepted 30 January 2021

Check for updates

(c) Author(s) (or their employer(s)) 2021. Re-use permitted under CC BY-NC. No commercial re-use. See rights and permissions. Published by BMJ.

'Department of Anthropology, Human Rights Institute, University of Connecticut, Storrs, Connecticut, USA

${ }^{2}$ Institute of Social and Cultural Anthropology, Freie Universität Berlin, Berlin, Germany

${ }^{3}$ Science, Technology, and International Affairs Program, School of Foreign Service, Georgetown University, Washington, DC, USA ${ }^{4}$ Institute for the Study of Societal Issues, University of California Berkeley, Berkeley, California, USA

${ }^{5}$ NextSkills Consulting, Dhaka, Bangladesh

Correspondence to

Dr Sarah S Willen;

sarah.willen@uconn.edu

\section{ABSTRACT}

Health and the capacity to flourish are deeply intertwined. For members of vulnerable migrant groups, systemic inequalities and structural forms of marginalisation and exclusion create health risks, impede access to needed care and interfere with the ability to achieve one's full potential. Migrants often have limited access to healthcare, and they frequently are portrayed as less deserving than others of the resources needed to lead a healthy and flourishing life. Under these circumstances, clinicians, healthcare institutions and global health organisations have a moral and ethical obligation to consider the role they can —and do — play in either advancing or impeding migrants' health and their capacity to flourish. Drawing on case studies from three world regions, we propose concrete steps clinicians and health institutions can take in order to better serve migrant patients. These include recommendations that can help improve understanding of the complex circumstances of migrants' lives, strengthen collaboration between care providers and non-medical partners and transform the social, economic and structural circumstances that impede flourishing and harm health. Developing new strategies to promote the flourishing of precarious migrants can strengthen our collective ability to re-envision and redesign health systems and structures to value the health, dignity and bodily integrity of all patients - especially the most vulnerable - and to promote flourishing for all.

\section{INTRODUCTION}

How are human health and human flourishing inter-related? What role can clinicians and healthcare institutions play in supporting patients' pursuits of both a healthy and a flourishing life? What obligations do healthcare providers, clinics and hospitals, healthfocused non-governmental organisations (NGOs) and global health organisations hold towards unauthorised migrants, asylum seekers, refugees and other vulnerable migrant groups?
Summary box

Health is deeply interconnected with humans' ability to flourish—-to lead a 'good life', shape their future and achieve their potential.

- Migrants' health and flourishing are often impeded by structural exclusions as well as negative portrayals that cast them as undeserving of collective attention, investment or care.

- Healthcare providers, institutions and clinical training programmes have vital roles to play in promoting migrants' health and their capacity to flourish, both individually and collectively.

- Flourishing means different things to different people and in different communities and cultural settings.

- Healthcare professionals must recognise that flourishing is an active pursuit influenced by cultural expectations, social relationships, and the social, political and economic structures that shape people's lives.

- Supporting the health and flourishing of vulnerable migrants and other excluded groups requires new tools, more expansive approaches to care provision and collaborative models that reach beyond the health domain.

Drawing on our experience as a group of social scientists and clinicians who have worked with precarious migrants in and from Asia, Africa, Europe, North America and the Middle East, we know that even under the best of circumstances, many migrants have difficulty being seen, heard and recognised by healthcare providers as full human beings whose lives involve more than just their migration status. $^{1-4}$

As the COVID-19 pandemic has only made clearer, ${ }^{5}$ migrants' health often is treated as less deserving of attention and investment than other groups, ${ }^{6-8}$ and migrants with precarious status often are shunted away systematically from mainstream systems of care and coverage. ${ }^{9}$ When care is accessible, barriers of language, education, socioeconomic status, racialised identity, culture and religion can impede patient-provider 
Definition box

\section{Flourishing}

We define the pursuit of flourishing as an active process of striving to live in keeping with one's defining values, commitments and vision for the future, as individuals and in the context of one's family and the communities to which one belongs. ${ }^{28} 30$ Definitions of flourishing vary, but most build from Aristotle's notion of eudaimonia, variously translated as 'flourishing' or 'a good life'.

Flourishing is not simply a psychological state, but an active pursuit informed by cultural expectations and social relationships, and influenced by the social, political and economic structures that shape people's lives.

Flourishing differs from resilience, which involves the capacity to bounce back from, or function despite, adversity. ${ }^{48}$ It also differs from well-being, although the two are sometimes used interchangeably. ${ }^{31}$ Unlike resilience and well-being, flourishing is not a state or condition, but a dynamic, ongoing pursuit. Since it means different things to different people in different communities and cultural settings, flourishing cannot be defined in universal terms.

For migrants, the pursuit of flourishing often extends beyond national and continental borders.

communication. Lack of insurance can obstruct access to comprehensive treatment and follow-up care. ${ }^{10}$ In some settings, NGOs or charity-based clinics are migrants' best, or only, options. ${ }^{11}$ In public, private and NGO settings alike, clinicians often have limited awareness of migrants' social, political and economic circumstances, and misunderstanding and bias, overt or implicit, can impede clinical rapport. ${ }^{12}$ All of these obstacles can harm migrants' health and diminish their capacity to flourish.

What can clinicians do to promote human flourishing when so many of these factors lie outside the clinical domain? Certainly, clinicians and health institutions cannot be expected to resolve the profound inequities that harm health and impede patients' capacity to achieve their full potential. They can, however, broaden their gaze and re-envision their roles and responsibilities in light of the multiple barriers that often deny migrants and other vulnerable and minoritised patients the resources needed to live-and the chance to be recognised as worthy of living-full and meaningful lives.

This article is grounded in four claims. First, health is fundamental to humans' ability to flourish-to lead a good life, to 'shape one's future, 13 and to achieve one's potential. ${ }^{14-17}$

Second, for many people whose migration status or background renders them vulnerable-including those who lack papers, seek asylum or hold refugee status-both health and the capacity to flourish are imperilled by what social scientists describe as structural vulnerability. ${ }^{18-20}$ Put simply, migrants often are consigned to positions of disadvantage within social and political hierarchies in ways that expose them to health risks, limit their ability to access needed care and curtail their capacity to realise their capabilities or achieve their potential. At the same time, migrants often are portrayed in political, policy and

\section{Case 1. Mr S: When health is not enough}

One summer evening, Mr S appeared at a non-governmental organisation (NGO)-run clinic in Tel Aviv requesting the impossible. ${ }^{28}$ He and his fiancée, Ms R, both undocumented migrants from Ghana, were determined to marry in a Catholic ceremony. But before a wedding date could be set, the local parish required several documents, including a doctor's letter attesting that neither had HIV. Yet, both Mr S and Ms R had recently been diagnosed with HIV and were receiving antiretroviral (ARV) treatment via another local NGO. On that clinic visit, Mr S laid bare his dilemma. He was desperate to marry his bride. But he was just as desperate to keep their secret. If people found out they had HIV, he explained, 'we would be cut off from the community. I would die first'-he noted, at his own hand, if need be.

Physically, Mr S's health was much improved. But emotionally, he was in dire straits. Simply surviving was no longer enough. Now, he and Ms R wanted to flourish-to live in keeping with values and life commitments 'so deep' that they 'would not know themselves' without them. ${ }^{30}$ For Mr S, this included commitments to his bride, his community, his reputation and his faith by marrying in a Catholic ceremony.

In Mr S's case, the potential dangers of HIV-related stigma were profound. His threats of suicide were genuine. Yet, a reasonable solution was fully in reach. With discretion, a clinic volunteer reached out to a parish priest who was sympathetic to the couple's concerns and arranged a private meeting to discuss their predicament. At the meeting, the priest received assurances from Mr S and Ms R that each was fully informed of the other's health status and that they shared a hope to have healthy children, which would be medically possible with appropriate ARV treatment and NGO support. Satisfied by their discreet conversation, the priest authorised their wedding and agreed to keep their health status in confidence. The celebration was a joyous one-a vital step in the bride and groom's pursuit of a flourishing life.

public conversations as less 'deserving' than others ${ }^{6-8}$ of the kinds of recognition and societal investment that promote both flourishing and health.

Third, given the inter-relationship between flourishing and health and the precarity that vulnerable migrants face, clinicians, healthcare institutions and health organisations at all levels have a moral and ethical obligation to consider the role they can-and do-play in either advancing or impeding migrants' capacity to flourish.

Finally, developing new strategies to promote the flourishing of precarious migrants can strengthen our collective ability to re-envision and redesign health systems and structures to value the health, dignity and bodily integrity of all patients and to promote flourishing for all.

As we elaborate below, there are concrete steps that clinical educators, care providers and institutions can take as part of these broader efforts to promote health equity and justice. One key step is to understand the profound and reverberating ways in which global as well as regional and local 'structures, systems, and economies' affect health. ${ }^{21}$ Another, we contend, is to recognise the deep interconnections between health and flourishing. As public health visionary Michael Marmot explains, 
Case 2. Ms A: Clinical failures and the pursuit of integrated healing

Ms A, a first-generation Turkish-German migrant, was treated for chronic depression by German psychiatrists and prescribed Gesprächstherapie, or talk-based therapy, and an antidepressant. ${ }^{50}$ Yet, Ms A's condition did not improve. Instead, she grew disillusioned with the German medical landscape and her clinicians' inability to treat what she described as her 'psychological problems' ( $p$ sychische Probleme) and 'suffering of the soul' (seelisches Leid).

It was not until Ms A became involved with a Sufi Muslim community that she was able to begin healing. In Berlin, this TurkishGerman community centre provided community and support, including care, through Sufi healing practices. ${ }^{51}$ The centre was a welcoming space, created for and by Muslim migrants, that supported her individual pursuit of flourishing in an affirmative, non-discriminatory setting and familiar idiom. In this safe community space, Ms A found an alternative set of healing practices, grounded in Sufi tradition, that she described affirmingly as 'spiritual psychiatry'. ${ }^{50}$ Eventually, she gave up both medication and Gesprächstherapie. Through involvement in a community that acknowledged and responded to her emotional and spiritual needs, Ms A finally was able to shift her perception in ways that improved her mental health and helped her flourish.

'we need social action to create the conditions, to quote [Amartya] Sen, for people to lead lives they have reason to value.' 14

\section{MIGRATION AND HEALTH IN SOCIAL CONTEXT}

The relationship between flourishing and health is a fast-growing area of interest. Researchers in medicine, ${ }^{22}$ nursing, ${ }^{2324}$ bioethics $^{1725}$ and public health ${ }^{1426}$ agree that the ability or inability to flourish has important implications for health. Our experience studying and working for migrant health in diverse settings supports this view, while also foregrounding five vital concerns.

First, the capacity to flourish depends on having one's basic material and psychosocial needs met. Migrants often face adversities that co-occur and interact, including social, political, financial and structural constraints. ${ }^{102728}$

Second, flourishing is not just a psychological state of 'optimal mental health'. ${ }^{29}$ Rather, as both Mr S (Box 1) and Ms A's stories (Box 2) make clear, people's pursuits of flourishing involve deeper, longer term existential goals that can intersect with-and often extend far beyondwhat transpires in clinical encounters. These pursuits may be influenced by sociocultural or religious expectations and by others in migrants' lives, including close friends and relatives, and by the larger (local and transnational) communities to which they belong. ${ }^{25} 2830$

Third, flourishing cannot be defined in universal terms. Understandings of a 'good life' vary widely not just across social, political, cultural and religious settings, but even among people who might, from a demographic standpoint, appear to have much in common. In short, scales and metrics designed to measure flourishing, ${ }^{31-33}$ either independently or in relation to health, must be employed with caution. The same holds true for efforts
Case 3. Ms J: 'Women-Friendly Spaces' for healing from trauma

Ms $\mathrm{J}$ is one of over 440000 Rohingya women and girls who reside in the world's largest refugee settlement, Cox's Bazar in Bangladesh. ${ }^{52}$ Many refugees like Ms J have survived mass violence in Myanmar and also gender-based violence (GBV). Deep-rooted patriarchy and conservative views among Rohingya refugees have prevented Ms J, and many other women, from accessing and following up with clinical care. Struggles to communicate because of language barriers, cultura differences and reluctance to verbalise intimate harms can also make it difficult for clinicians to understand and treat patients who have experienced GBV. Strict reporting protocols impede efforts to build trust, and they deter women like Ms J from returning for follow-up care. On its own, clinical care often is not enough to promote women's recovery and healing.

For Ms J and other Rohingya women and girls, 'women-friendly spaces' (WFS), or Shanti khana, Rohingya for 'home of peace', can play a vital role in overcoming these barriers. Such spaces are sponsored and run by humanitarian organisations for Rohingya women and girls. WFS function as support hubs where women can seek critical services such as case management, health referrals and accompaniment to medical and legal service points. Ms J, who carried 'bad memories' of the violence in Myanmar, explained, 'We feel good when we come to Shanti khana... We have received dignity kits, solar lights to go to the toilet at night. If I face any problem, I come here to talk to these sisters.' These 'sisters' include Rohingya psychosocial volunteers as well as staff members who visit women like Ms $\mathrm{J}$ in their homes to identify GBV survivors and introduce them to places like Shanti khana, where they can find support and feel secure.

Such spaces ensure a collective sense of safety and well-being, provide opportunities to socialise and make friends, and enable women to give as well as receive emotional support. They give Rohingya women a chance to recover medically from the physical and psychological harms of GBV, and to 'shape [their] future ${ }^{13}$ and lead 'lives they have reason to value', ${ }^{14}$ individually and collectively.

to bring flourishing measures into the clinic. ${ }^{22}$ As Mr S's story (Box 1) underscores, adequate medical treatment alone may not, on its own, be enough to help a patient flourish.

Fourth, community solidarity, communal support and forms of collective action can be powerful tools for promoting migrants' capacity to flourish. As Ms J's story (Box 3) makes clear, mechanisms of community solidarity and support, formal and informal, can strengthen migrants' efforts to make healthy choices, access needed care, adhere to medical guidance-and demand action when access to care, or to the social determinants of good health, is constrained or curtailed. On a broader level, collective efforts to understand and confront the 'social dynamics that affect population health'-or 'the social determination of health '34 _ can advance migrants' collective flourishing in ways that clinicians can and should support.

Finally, migrants' pursuits of a flourishing life may come in tension, or even conflict, with the values and priorities of healthcare providers and health institutions (Box 2). These tensions can create clinical dilemmas and 
treatment challenges, especially when migrants' priorities appear to run counter to those of clinicians, healthcare institutions or global health organisations-or to migrants' own well-being. ${ }^{35}$

For instance, clinicians tend to assume that health issues are a top priority for their patients. After all, health concerns precipitate clinical encounters in the first place. As both Mr S and Ms A's stories illustrate, however, health considerations may not take precedence, or appear to take precedence, in precisely the ways that clinicians expect. Health issues can be deeply entwined with other challenges migrants confront as they struggle to lead stable, secure and flourishing lives. Mr S's case, for instance, shows how supporting migrant patients may require a holistic and expansive view of what flourishing entails-and a correspondingly flexible model of clinical care that includes liaising with unconventional partners.

If Mr S's case results in success, Ms A's tells a very different story-a story of how medicine can fail migrant patients. Her experience raises important questions about how such failures might be anticipated and avoided. Both cases point to ways in which clinicians and healthcare institutions can partner with non-clinical and communitybased systems of solidarity and care to support migrants' flourishing while also promoting their health.

Healing and flourishing are intertwined, and both have collective as well as individual dimensions-especially for migrants who have experienced trauma, as Ms J's story makes clear. For individuals and communities to flourish after suffering extraordinary trauma, clinical intervention may be vital but insufficient on its own. Emotional wounds are invisible, and recovery requires feeling secure, heard and supported as individuals and as part of a larger community. Women-friendly spaces like Shanti khana, which attend to both physical harms and collective trauma, can help migrants pursue opportunities to heal, recover and flourish — both individually and collectively.

\section{FLOURISHING: IMPLICATIONS FOR GLOBAL HEALTH CLINICIANS, SYSTEMS AND POLICIES}

These insights have implications for clinical care, clinical training and health policy and planning. When migrants are consigned to positions of structural vulnerability that endanger their health and limit their ability to access healthcare, and when they are portrayed as less deserving than others of the resources needed to achieve their full potential, health stakeholders have a moral and ethical obligation to look, and think, beyond the confines of the clinical encounter.

Clinicians and healthcare institutions can bolster migrant patients' opportunities to flourish in multiple ways.

- Clinicians, clinicians in training and others employed in health settings and health organisations should be trained in structural competency and cultural humility. ${ }^{36}{ }^{37}$ With these tools in hand, providers and health institutions can better recognise how laws and policies, power dynamics, material needs and sociocultural and religious obligations can influence clinical encounters and health trajectories. As a result, they will be better equipped to confront obstacles to flourishing and health that stem from language and sociocultural differences, bureaucracy, discrimination and poverty.

- Healthcare providers must learn to recognise that flourishing means different things to different people in different communities—and ask questions that can help them understand and work to meet their patients' needs. This means taking time to understand why migrant patients' needs or concerns may diverge from routine clinical care, and to consider with an open mind why patients may be unable or unwilling to meet clinicians' expectations or follow recommendations.

- On a related note, health providers and institutions must develop the skills and infrastructure needed for effective partnership and collaboration between care providers and non-medical organisations and institutions-including stakeholders in law, public health and human rights. ${ }^{38}$ Clinical interventions alone will not promote flourishing —or health—among migrant patients. But clinicians can develop new modes of 'prescribing'for instance, by using integrative healing strategies in the same way some primary care clinicians prescribe food, and some paediatricians prescribe books or reading. ${ }^{39-41}$ They can partner with rights organisations to document abuses that harm migrants' health, violate their rights and diminish their capacity to realise their full potential. Legal-medical partnerships can help confront upstream obstacles to flourishing and health by calling attention to root causes and political determinants. ${ }^{42}$ Finally, integrative care models that work across medical, legal, social, cultural and/or religious sectors (eg, women-friendly spaces, self-care interventions based on a logic of 'expert-patients', ${ }^{43}$ approaches to 'syndemic care, ${ }^{44}$ ) can serve as useful models.

- Health professionals and healthcare organisations can work to transform social, economic and structural circumstances that impede flourishing and harm health-for migrants and for other vulnerable patients and communities. Clinicians can use their social position to engage in collective organising to support vulnerable migrant groups and others who have been ignored or harmed by the determining impact of social, political and economic circumstances. Both within their institutions and in broader public and policy conversations, care providers and healthcare institutions can insist on naming, documenting and tackling health inequities that simultaneously harm their patients' health and curtail their capacity to shape their futures and realise their full potential. Avenues of action include professional associations, NGOs like 'Physicians for Human Rights-Israel', ${ }^{28}$ networks like 'Medibüro Berlin' in Germany ${ }^{45} 46$ and movements like 'White Coats for Black Lives' in the USA. ${ }^{47}$ 
Vulnerable migrants face multiple forms of adversity, discrimination and hardship, and many struggle long and hard just to arrive at the clinic door. Yet, migrants, like members of other minoritised and vulnerable groups, are not simply passive victims of their social, economic or political positions. Ultimately, health care providers can foster migrant patients' pursuits of flourishing by recognising them as unique, complex individuals whose defining values, commitments and visions for the future are as significant, and deeply felt, as providers' own—and, moreover, who are equally deserving of health-related attention, investment and care.

Twitter Sarah S Willen @sarahwillen, Nasima Selim @NasimaSelim, Emily Mendenhall @mendenhall_em and Hansjörg Dilger @h_dilger

Acknowledgements The authors are deeply grateful to their interlocutors and front-line workers in migratory contexts across the Global North and South, whose everyday struggles and strivings to flourish educate and inspire them. This work was made possible by a generous grant to EM from Georgetown University's Global Futures Initiative. NS's contribution resulted from a PhD thesis grant awarded by the German Academic Exchange Service (DAAD). SSW's contribution benefited from support from the U.S. National Science Foundation (No. 0135425), the Social Science Research Council, the Wenner-Gren Foundation, and the Robert Wood Johnson Foundation (Grant No. 74898). The authors also acknowledge the contributions of Georgetown University, DAAD and UC Berkeley in financially supporting the workshop 'Migration and Health' (20-21 February 2020, Georgetown University) at which this article was initially drafted.

Collaborators The Working Group on Migration and Health in Social Context, including: John Fredrik Askjer, University of Oslo; Lauren Carruth, American University; Ernesto Castañeda, American University; Heide Castañeda, University of South Florida; Shahanoor Akter Chowdhury, NextSkills Consulting, Dhaka, Bangladesh; Yusupha Dibba, Partners in Health, Sierra Leone; Hansjörg Dilger, Freie Universität Berlin; Katharine M. Donato, Walsh School of Foreign Service, Georgetown University; Heidi E. Fjeld, University of Oslo; Raphael Frankfurter; University of California San Francisco; Jérémy Geeraert, Humboldt University Berlin and Centre Marc Bloch; Seth M. Holmes, University of California Berkeley and University of California San Francisco; Anne Kveim Lie, University of Oslo; Miriam Magaña Lopez, University of California Berkeley; Carlos Martinez, University of California Berkeley; Emily Mendenhall, Walsh School of Foreign Service, Georgetown University; Carlos Piñones-Rivera, Universidad Arturo Prat; Ursula Probst, Freie Universität Berlin; James Quesada, San Francisco State University; Nasima Selim, Freie Universität Berlin; Lahra Smith, Walsh School of Foreign Service, Georgetown University; Sarah S. Willen, University of Connecticut; and Nina Zeldes, Freie Universität Berlin. Additional collaborators include Colleen C. Walsh, Cleveland State University; Abigail F. Williamson, Trinity College; William Tootle, University of Connecticut; and Mikayla Hyman, Middlebury College.

Contributors All authors have experience conducting qualitative and ethnographic research in migratory contexts. SSW, NS, EM, MML and HD collaborated in producing the first draft of the article, and SAC subsequently contributed case material. SSW led the writing, and all authors reviewed and approved the final version. SSW is the guarantor. Additional contributors: members of the Working Group on Migration and Health in Social Context.

Funding This work was funded by Deutscher Akademischer Austauschdienst, University of California Berkeley, Georgetown University, Georgetown University (Global Futures Initiative Grant).

Disclaimer The views expressed are those of the authors and do not represent the views of the institutions to which they are affiliated, and do not necessarily reflect the views of the Robert Wood Johnson Foundation or other funding agencies.

Competing interests None declared.

Patient and public involvement Patients and/or the public were not involved in the design, or conduct, or reporting, or dissemination plans of this research.

Patient consent for publication Not required.

Provenance and peer review Not commissioned; internally peer reviewed.

Data availability statement No data are available.
Open access This is an open access article distributed in accordance with the Creative Commons Attribution Non Commercial (CC BY-NC 4.0) license, which permits others to distribute, remix, adapt, build upon this work non-commercially, and license their derivative works on different terms, provided the original work is properly cited, appropriate credit is given, any changes made indicated, and the use is non-commercial. See: http://creativecommons.org/licenses/by-nc/4.0/.

\section{ORCID iDs}

Sarah S Willen http://orcid.org/0000-0002-0827-0510

Nasima Selim https://orcid.org/0000-0001-6626-762X

Emily Mendenhall https://orcid.org/0000-0002-5826-1321

Hansjörg Dilger https://orcid.org/:0000-0002-8493-4286

\section{REFERENCES}

1 Falge C, Ruzza C, Schmidtke O. Migrants and health: political and institutional responses to cultural diversity in health systems. Farnham, Surrey, England: Burlington, VT: Ashgate, 2012.

2 Willen SS, Knipper M, Abadía-Barrero CE, et al. Syndemic vulnerability and the right to health. Lancet 2017;389:964-77.

3 Spitzer DL, Torres S, Zwi AB, et al. Towards inclusive migrant healthcare. BMJ 2019;366:I4256.

4 International Organisation for Migration. World migration report; 2018. https://www.iom.int/sites/default/files/country/docs/china/r5_ world_migration_report_2018_en.pdf [Accessed 3 March 2021].

5 Liem A, Wang C, Wariyanti Y, et al. The neglected health of international migrant workers in the COVID-19 epidemic. Lancet Psychiatry 2020;7:e20

6 Willen SS. Migration, "illegality," and health: mapping embodied vulnerability and debating health-related deservingness. Soc Sci Med 2012;74:805-11.

7 Willen SS, Cook J. Health-Related Deservingness. In: Thomas F, ed. Handbook of migration and health. Cheltenham: Edward Elgar, 2016.

8 Holmes S, Castañeda E, Geeraert J, et al. Deservingness: migration and health in social context. BMJ-Global Health 2021;0. doi:10.1136/bmjgh-2021-005107

9 Castañeda H. Im/migration and health: conceptual, methodological, and theoretical propositions for applied anthropology. NAPA Bull 2010;34:6-27.

10 Castañeda H, Holmes SM, Madrigal DS, et al. Immigration as a social determinant of health. Annu Rev Public Health 2015;36:375-92.

11 Ticktin M. Where ethics and politics meet: the violence of Humanitarianism in France. American Ethnologist 2006;33:33-49.

12 Dilger H, Leissner L, Bosanska L, et al. Illness perception and clinical treatment experiences in patients with M. Maroteaux-Lamy (mucopolysaccharidosis type $\mathrm{VI}$ ) and a Turkish migration background in Germany. PLoS One 2013;8:e66804.

13 Alkire S. Briefing Note. Capability and Functionings: Definition \& Justification. Boston: Human Development and Capability Association, 2005.

14 Marmot M. Capabilities, human flourishing and the health gap. $J$ Human Dev Capabil 2017;18:370-83.

15 Nussbaum M. Women and human development: the capabilities approach. Cambridge: Cambridge University Press, 2000.

16 Sen A. Development as freedom. New York: Anchor Books, 2000.

17 Prah Ruger J. Positive public health ethics: toward Flourishing and resilient communities and individuals. Am J Bioeth 2020;20:44-54.

18 Carruth L, Martinez C, et al, Global Migration Working Group. Structural vulnerability: migration and health in social context. BMJGlobal Health 2021.

19 Quesada J, Hart LK, Bourgois P. Structural vulnerability and health: Latino migrant laborers in the United States. Med Anthropol 2011;30:339-62.

20 Bourgois P, Holmes SM, Sue K, et al. Structural vulnerability: Operationalizing the concept to address health disparities in clinical care. Acad Med 2017;92:299-307.

21 Metzl JM, Maybank A, De Maio F. Responding to the COVID-19 pandemic: the need for a structurally competent health care system. JAMA 2020;324:231.

22 VanderWeele TJ, McNeely E, Koh HK. Reimagining HealthFlourishing. JAMA 2019;321:1667.

23 Agenor C, Conner N, Aroian K. Flourishing: an evolutionary concept analysis. Issues Ment Health Nurs 2017;38:915-23.

24 Hewitt J. Just healthcare and human flourishing: why resource allocation is not just enough. Nurs Ethics 2019;26:405-17.

25 Parens E, Johnston J, eds. Human flourishing in an age of gene editing. New York, NY: Oxford University Press, 2019. 
26 Bethell CD, Gombojav N, Whitaker RC. Family resilience and connection promote Flourishing among US children, even amid adversity. Health Aff 2019;38:729-37.

27 Mendenhall E. Syndemic suffering: social distress, depression, and diabetes among Mexican immigrant women. Walnut Creek, CA: Left Coast Press, 2012.

28 Willen SS. Fighting for Dignity: Migrant Lives at Israel's Margins. Philadelphia: University of Pennsylvania Press, 2019.

29 Keyes CLM. The mental health continuum: from languishing to flourishing in life. J Health Soc Behav 2002;43:207-22.

30 Mattingly C. Moral laboratories. Berkeley: University of California Press, 2014

31 Diener E, Wirtz D, Tov W, et al. New well-being measures: short scales to assess Flourishing and positive and negative feelings. Soc Indic Res 2010:97:143-56.

32 Seligman M. PERMA and the building blocks of well-being. J Posit Psychol 2018;13:333-5.

33 VanderWeele TJ. On the promotion of human flourishing. Proc Natl Acad Sci U S A 2017;114:8148-56.

34 Spiegel JM, Breilh J, Yassi A. Why language matters: insights and challenges in applying a social determination of health approach in a north-south Collaborative research program. Global Health 2015;11:9.

35 Tiilikainen M, Koehn PH. Transforming the boundaries of health care: insights from Somali migrants. Med Anthropol 2011;30:518-44.

36 Metzl JM, Hansen $\mathrm{H}$. Structural competency: theorizing a new medical engagement with stigma and inequality. Soc Sci Med 2014;103:126-33.

37 Tervalon M, Murray-García J. Cultural humility versus cultural competence: a critical distinction in defining physician training outcomes in multicultural education. J Health Care Poor Underserved 1998;9:117-25.

38 Zeldes N, Dilger H, FitzGerald K, et al. Transnational patients: practical and ethical implications for medical practices and health promotions policy. World Med Health Policy 2018;10:198-207.

39 Needlman R, Klass P, Zuckerman B. Reach out and get your patients to read. Contemporary Pediatrics 2002;19:51-69.
40 Geiger J. The unsteady March. Perspect Biol Med 2005;48:1-9.

41 Alderwick HAJ, Gottlieb LM, Fichtenberg CM, et al. Social prescribing in the U.S. and England: emerging interventions to address patients' social needs. Am J Prev Med 2018;54:715-8.

42 League A, Donato KM, Sheth N, et al. A systematic review of medical-legal partnerships serving immigrant communities in the United States. J Immigr Minor Health 2021;23:163-74.

43 Guell C. Self-Care at the margins: meals and meters in migrants' diabetes tactics. Med Anthropol Q 2012;26:518-33.

44 Mendenhall E, Kohrt BA, Norris SA, et al. Non-communicable disease syndemics: poverty, depression, and diabetes among lowincome populations. Lancet 2017;389:951-63.

45 Castañeda H. Medical aid as protest: acts of citizenship for unauthorized $\mathrm{im} / \mathrm{migrants}$ and refugees. Citizensh Stud 2013;17:227-40.

46 Huschke S, deservingness P. Performing deservingness. humanitarian health care provision for migrants in Germany. Soc Sci Med 2014;120:352-9.

47 White Coats for Black Lives (WC4BL) National Working Group. \#BlackLivesMatter: Physicians must stand for racial justice. AMA J Ethics 2015;17:978-82.

48 Panter-Brick C. Health, risk, and resilience: interdisciplinary concepts and applications. Annu Rev Anthropol 2014;43:431-48.

49 Cylus J, Smith PC. The economy of wellbeing: what is it and what are the implications for health? BMJ 2020;369:m1874.

50 Selim N. Learning the ways of the heart in Berlin. Sufism, anthropology, and the Post-Secular condition. PhD thesis. Institute of Social and Cultural Anthropology, Freie Universität Berlin, 2019.

51 Selim N. Sufi body practices and therapeutic politics in Berlin. In: Klinkhammer G, Tolksdorf E, eds. Somatisierung des Religiösen. Empirische Studien zum rezenten religiösen Heilungs -und Therapiemarkt. Bremen: Universität Bremen, 2015: 237-82.

52 Joint response plan Rohingya humanitarian crisis January-December 2020. Available: https://www.humanitarianresponse.info/sites/www. humanitarianresponse.info/files/documents/files/jrp_2020_summary_ 2-pager_280220.pdf 